Fourth International Conference on Sustainable Construction Materials and Technologies http://www.claisse.info/Proceedings.htm

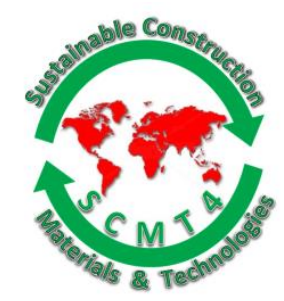

SCMT4

Las Vegas, USA, August 7-11, 2016

\title{
The Effect of Superabsorbent Polymers (SAP) on the Performance of Cementitious Materials
}

\author{
Khashayar Farzanian $^{1 \mathrm{a}}$, Yara Wehbe ${ }^{1 \mathrm{~b}}$, and Ali Ghahremaninezhad ${ }^{1 \mathrm{c}}$ \\ ${ }^{1}$ Department of Civil, Architectural, and Environmental Engineering, University of Miami, Coral Gables, \\ FL 33134, ${ }^{1 c}$ Email: 〈a.ghahremani@miami.edu>.
}

\begin{abstract}
In this study, the interaction between superabsorbent polymers (SAP) and cementitious materials during absorption and desorption, and the influence of SAP on the properties of cementitious materials were investigated. The effect of pore solution chemistry and mechanical pressure on the absorption of SAPs was examined. The role of capillary action on the desorption of hydrogels was elucidated. The mechanical strength of cement pastes was assessed using the compressive strength test and electrical impedance spectroscopy (EIS) was utilized to evaluate the electrical resistivity of the cement pastes modified with SAP. It was shown that the effect of divalent $\mathrm{Ca}^{2+}$ is more pronounced than that of monovalent $\mathrm{Na}^{+}$on SAP absorption. The mechanical pressure was shown to strongly affect the absorption capacity of SAP. Capillary action was observed to significantly accelerate the desorption rate of hydrogels. The compressive strength of cement pastes with SAP was shown to be lower than the control cement paste. The electrical resistivity of the cement pastes with SAP was observed to increase compared to the control cement paste with the same total water/cement ratio used here.
\end{abstract}

\section{INTRODUCTION}

Autogenous shrinkage cracking constitutes a major concern in high performance concrete structures characterized with a low water/cement ratio (Sensale \& Goncalves 2014) (Jensen \& Hansen 2002). These cracks form in high performance cementitious materials due to the development of high capillary pressure in pores as a result of a reduction in relative humidity during hydration as water reacts with cement clinkers. Over the past several years, methods such as internal curing have been introduced to address the durability issues regarding the performance of high performance concrete. In internal curing, water is gradually supplied to the cement mixture from a source within the cement mixture during hydration to maintain high moisture level, thereby mitigating autogenous cracking (Sensale \& Goncalves 2014). Superabsorbent polymers (SAP) have been shown to have great potential for internal curing applications (Jensen \& Hansen 2002) (Mechtcherine \& Reinhardt 2012) (Jensen \& Hansen 2001). SAPs are acrylic acid -based hydrogels with a large water retention capacity, which can release water into cementitious materials in response to a reduction in relative humidity of the cementitious materials. One major advantage of SAP is the ability to tune its behavior such as capacity and absorption/desorption rate through designing its chemical composition. This permits a broader use of SAP in various cementitious material systems. In addition to reducing autogenous shrinkage cracking, water released from SAP can improve hydration thereby improving the microstructure of the cementitious materials near SAP (Bentz 2009) (Hasholt \& Jensen 
2015). The efficiency of SAP in reducing autogenous shrinkage of cementitious materials has been studied in the past (Mechtcherine et al. 2006) (Igarashi et al. 2006) (Dudziak et al. 2008) (Kovler \& Jensen 2005). Investigations (Hasholt \& Jensen 2015) (Lura et al. 2006) have also shown the potential of SAP in improving hydration in cementitious materials. The mechanical and durability characteristics of cementitious materials with SAP were studied by researchers (Schröfl et al. 2012) (Pourjavadi et al. 2013) (Snoeck et al. 2014) (Garboczi et al. 1996) (Jain \& Neithalath 2011) (Neithalath \& Jain 2010).

Understanding the behavior of hydrogels (SAP) including their absorption and desorption in a cementitious materials is necessary in the design of hydrogels for internal curing applications.

Hydrogels are expected to experience mechanical pressure during mixing and casting of cementitious materials; however, the effect of mechanical pressure on the behavior of hydrogels including their absorption/desorption capacity and rate has not received attention in the past. This paper aims to investigate the role of mechanical pressure and chemistry of pore solution on the absorption capacity and rate of hydrogels. The desorption of hydrogels with contact with porous materials was examined and compared to that in air. The influence of SAP on the mechanical properties and electrical resistivity of cement pastes was also evaluated.

\section{EXPERIMENTS}

\section{Materials and specimen preparation}

In this study a commercial hydrogel powder (SAP) made of sodium salt of acrylic acid was used to study the effect of mechanical pressure and ions on the absorption of hydrogel particles. The median particle size of the hydrogel powder was about $197 \mu \mathrm{m}$, determined by analyzing scanning electron images of hydrogel particles. An SEM image of dry hydrogel particles is shown in Figure 1a.

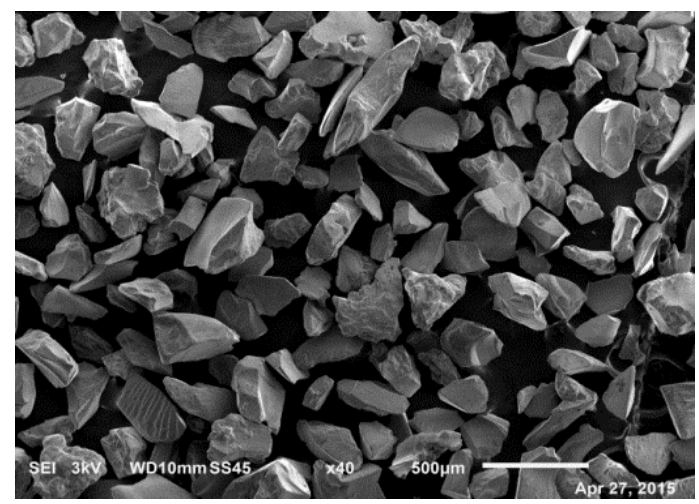

(a)

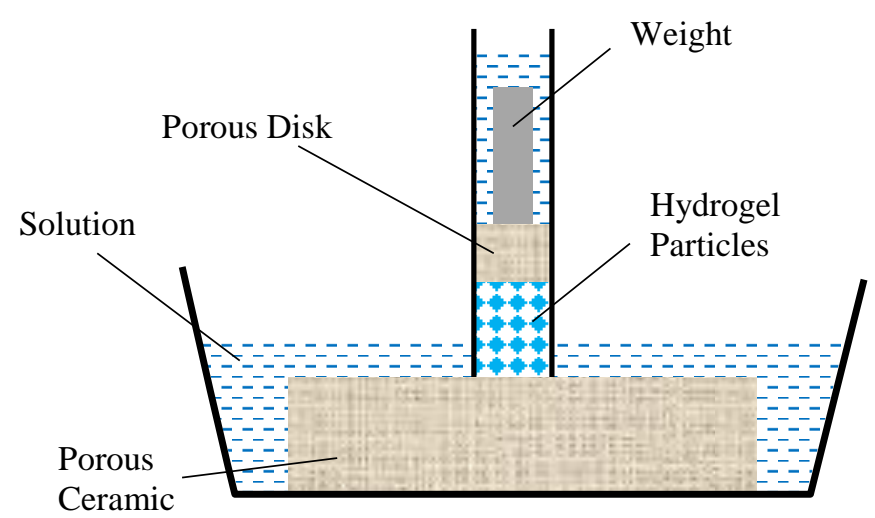

(b)

Figure 1. (a) Scanning electron microscopic image of hydrogel particles (SAP). (b) Schematic of the setup for measuring the effect of mechanical pressure on hydrogel particles absorption.

In order to investigate the effect of hydrogel particles on the performance of cementitious materials, cement pastes with $0.3 \%$ per cement mass addition of hydrogel particles were prepared. Type I Portland cement and a total water/cement ratio of 0.36 were used in the preparation of cement pastes. Cement pastes were cast in $50 \mathrm{~mm}$ cubic molds, sealed properly, and placed in a moist room with a relative humidity of more than $95 \%$ and temperature of $23 \pm 2{ }^{\circ} \mathrm{C}$. After $24 \mathrm{~h}$, the cement paste cubes were demolded and stored in a saturate lime solution until testing. The cubes were used in the compressive and electrical resistivity measurements. 
The desorption of hydrogels was studied using hydrogel blocks. The hydrogel was synthesized via free radical polymerization of acrylic acid monomers using a crosslinking agent. Then the hydrogel was fully swollen in distilled water for one day and then cut into blocks of $15 \mathrm{~mm}$ dimensions.

\section{Experimental methods}

\section{Absorption of hydrogel particles under mechanical pressure}

The effect of mechanical pressure on the absorption of hydrogel particles was evaluated using a setup comprised of a $19 \mathrm{~mm}$ diameter acrylic cylinder attached to a porous substrate at the bottom (see Figure 1b). The cylinder and the substrate were placed in a plastic container. Dry hydrogel particles were put into the cylinder to reach a thickness of about $3 \mathrm{~mm}$. Then a porous disk with a $10 \mathrm{~mm}$ thickness was placed on the top of the hydrogel particles and subjected to various weights. The cylinders and the containers were filled with $0.025 \mathrm{M}$ solutions of $\mathrm{NaCl}$ and $\mathrm{CaCl}_{2}$ to examine the effect of ion valence on the absorption of hydrogels. The change in the height of the top porous disk due to the absorption of hydrogel particles was measured by taking images of the cylinders at various times.

\section{Desorption of hydrogel}

The desorption of hydrogel blocks with contact with two porous substrates and also without contact was examined here. Two types of porous substrates were used. One was cement paste with nano and microscale pores and the other one was a porous ceramic with microscale pores. The surface of both porous substrates was polished with SiC sand papers with varied grit sizes of 180, 320, 600, and 1200 to achieve a smooth surface. Then the hydrogel blocks were placed on the substrates and their desorption measured using the volumetric change of the hydrogel blocks. Images of the hydrogel blocks were taken at various times to calculate the change in the volume of the hydrogel blocks. The desorption of hydrogels was conducted in a relative humidity of $60 \%$.

\section{Degree of hydration}

The degree of hydration of the cement pastes with hydrogel particles and the control cement pastes was studied at 6 days and 28 days of age. The non-evaporable water content was utilized to assess the degree of hydration of the cement pastes. A small piece of the cement pastes was ground, passed through the sieve \#60 and dried at $105^{\circ} \mathrm{C}$ for $24 \mathrm{~h}$. Then, the powder was ignited in a muffle furnace at $1050{ }^{\circ} \mathrm{C}$ for $3 \mathrm{~h}$. The non-evaporable water content was determined using the difference between the mass of the powder after and before ignition at $1050{ }^{\circ} \mathrm{C}$. The non-evaporable water content was corrected for the loss on ignition of cement assumed to be $2.75 \%$.

\section{Compressive strength test}

The compressive strength of the cement paste cubes with hydrogel particles and the control cement paste cubes was determined at 6 days and 28 days age. Compressive strength test was carried out using a SATEC compression machine. The average of three identical cubes was calculated and reported.

\section{Electrical resistivity test}

The electrical resistivity of the cement pastes at 6 days and 28 days of age was evaluated using EIS. In this method, an alternating signal (AC) with varying frequencies is passed through the cement paste cubes. The electrical resistivity is determined using the imaginary and real components of the response. The EIS measurement was conducted using a Reference Gamry 600 potentiostat/galvanostat with a $250 \mathrm{mV}$ AC current and a frequency range of $10^{6}$ to $10 \mathrm{~Hz}$. The electrical resistivity of the cement paste cubes was 
determined considering the geometry of the cubes. The average electrical resistivity of three identical cubes was calculated and reported.

\section{RESULTS AND DISCUSSION}

\section{Hydrogel absorption}

The results of hydrogel particles absorption in distilled water and ionic solutions are shown in Figure $2 \mathrm{a}$. The absorption of hydrogel particles in distilled water was interrupted due to inadequate height of the acrylic cylinder. The absorption of hydrogel particles in distilled water is expected to reach about $270 \mathrm{Vol} / \mathrm{Vol}$ from our previous experiments using the tea bag test. It is seen that the absorption of hydrogel particles is higher in distilled water than in $\mathrm{Na}^{+}$or $\mathrm{Ca}^{2+}$ solutions. Also, it appears that the effect of $\mathrm{Ca}^{2+}$ on decreasing the absorption of hydrogel particles is more than that of $\mathrm{Na}^{+}$. The reduction in the absorption of hydrogels in ionic solutions has been noted before and is attributed to the screening effect of ions reducing the electrostatic repulsion between anionic polymer networks (Horkay et al. 2001) (Horkay et al. 2000). The effect of mechanical pressure on the absorption of hydrogel particles in $\mathrm{Na}^{+}$and $\mathrm{Ca}^{2+}$ solutions is depicted in Figures $2 \mathrm{~b}$ and $2 \mathrm{c}$, respectively. The absorption was measured under pressures of $0 \mathrm{kPa}, 1.5 \mathrm{kPa}, 2.2$ $\mathrm{kPa}$, and $3.4 \mathrm{kPa}$. A decrease in the final absorption and absorption rate is realized in both solutions. The

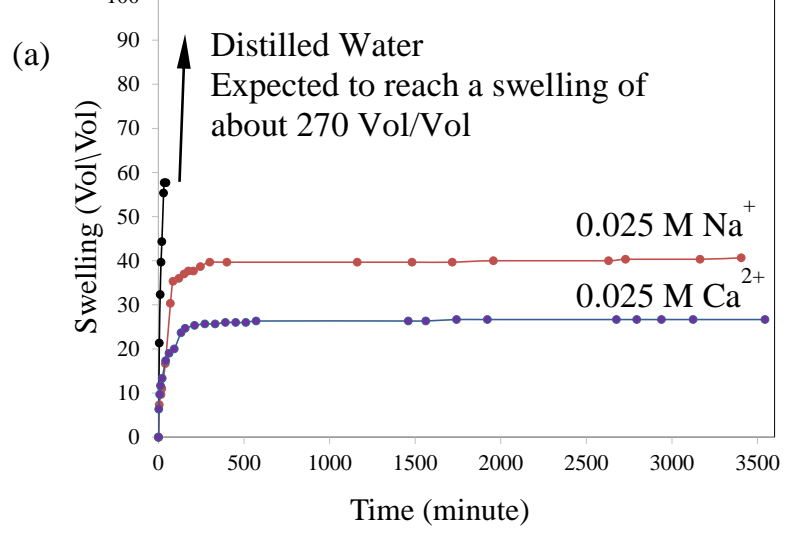

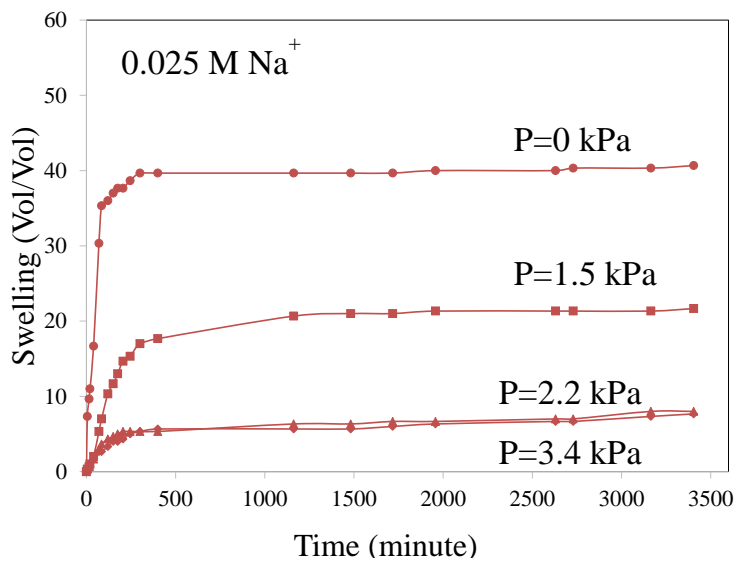

(b)

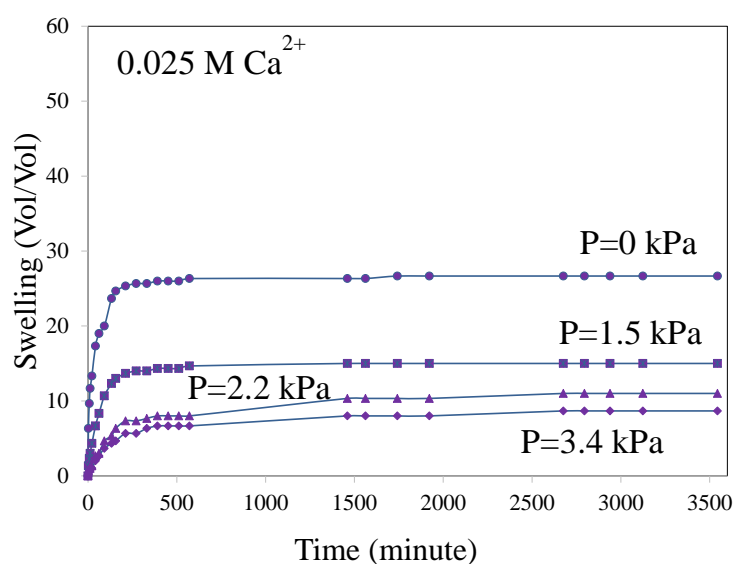

(c)

Figure 2. (a) Absorption of hydrogel particles in different solutions. Absorption of hydrogel in distilled water is expected to reach $270 \mathrm{Vol} / \mathrm{Vol}$. (b) and (c) Effect of mechanical pressure on the absorption of hydrogel particles in $\mathrm{Na}^{+}$and $\mathrm{Ca}^{2+}$ solutions, respectively. 
absorption of hydrogel particles in $\mathrm{Na}^{+}$solution did not appear to show a notable difference under mechanical pressures of $2.2 \mathrm{kPa}$ and $3.4 \mathrm{kPa}$. This difference is more pronounced in $\mathrm{Ca}^{2+}$ solution. The results presented above provide useful insight into the effect of pressure on the behavior of hydrogel particles. As mentioned previously, hydrogel particles are expected to undergo mechanical pressures during mixing and casting of cementitious mixture. Therefore, it is necessary to consider these effects in the design of hydrogel particles for internal curing applications.

\section{Desorption of hydrogels}

The results of desorption of hydrogels with contact with porous substrates are presented. The images showing the desorption of hydrogel blocks at various times are shown in Figure 3. The images corresponding to the desorption of a hydrogel block without contact with a porous substrate is also included for comparison. The variation of desorption with time is plotted in Figure 4. It is interesting to note the significant difference in desorption between the hydrogel block with contact with the cementitious substrate

$\mathrm{t}=0 \mathrm{~min}$

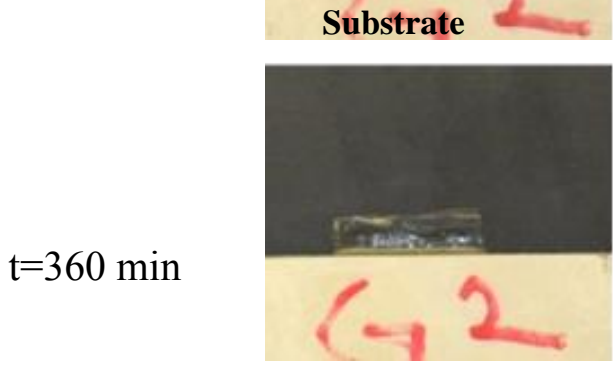

$\mathrm{t}=2610 \mathrm{~min}$

$\mathrm{t}=9990 \mathrm{~min}$
Cementitious Substrate
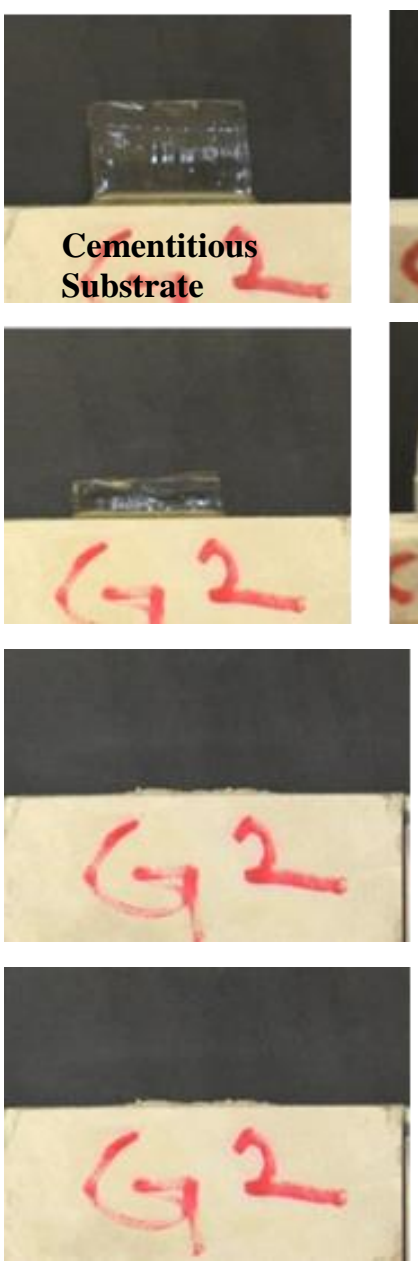
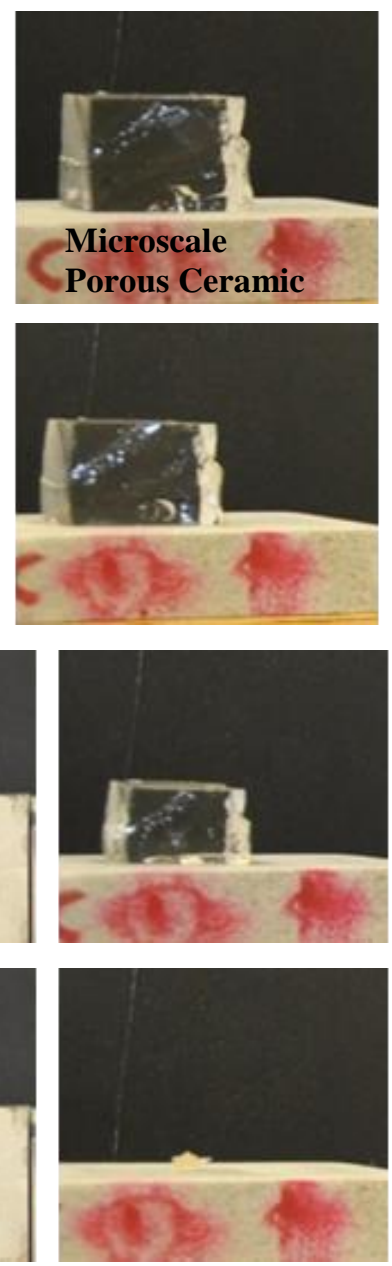
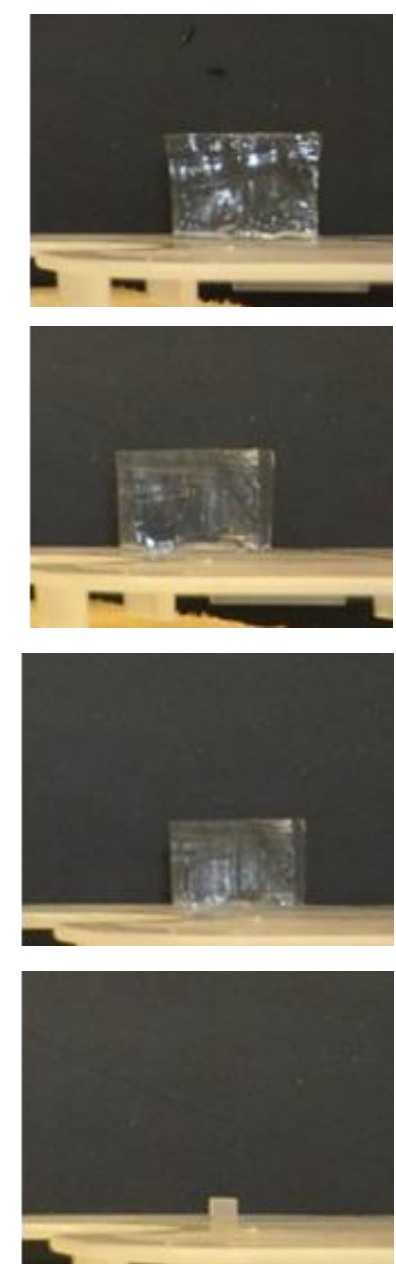

Figure 3. Images showing the desorption with time of hydrogel blocks with contact with a cementitious substrate (left), a microscale porous ceramic (middle), and without contact with a porous substrate (right). 


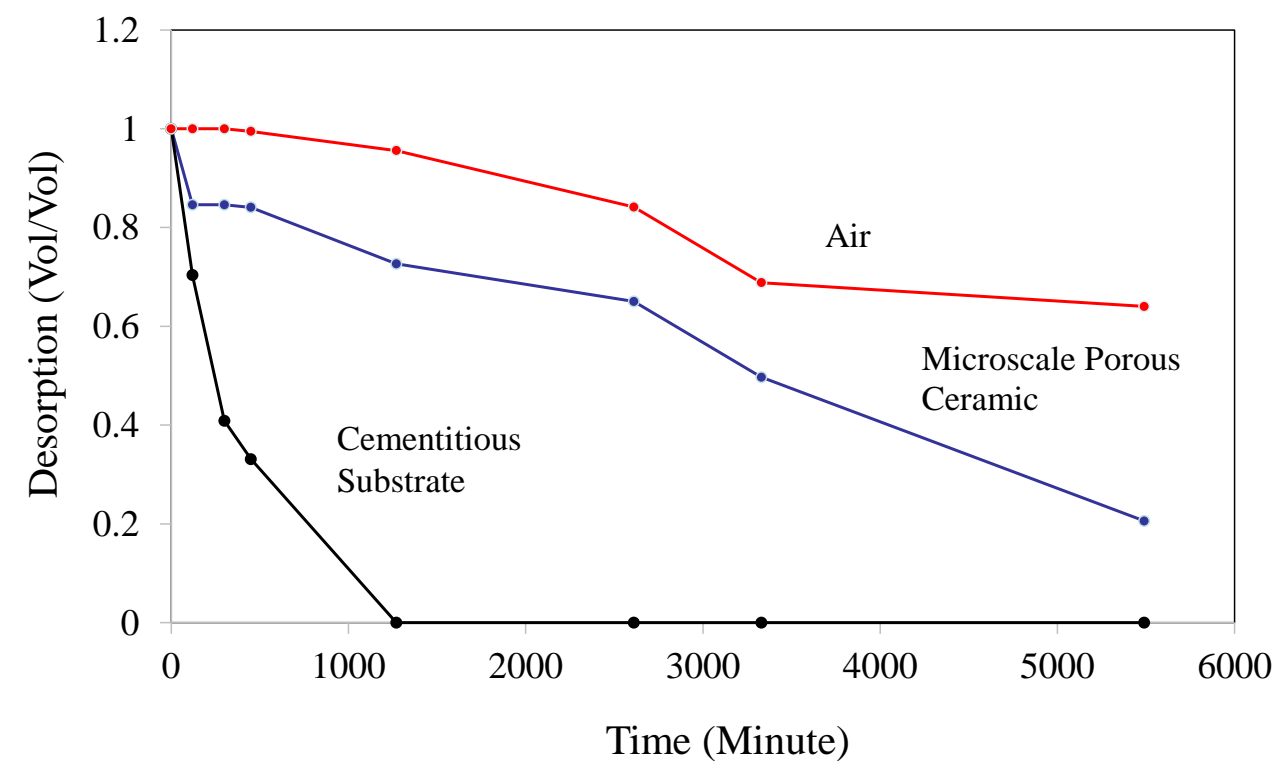

Figure 4. Desorption of hydrogel blocks indicating the effect of capillary forces.

and that with contact with porous ceramic or without any contact. The change in the morphology of hydrogel block during desorption revealed interesting features. It is noted that the desorption of hydrogel block with contact with cementitious substrate occurred mainly in the thickness direction and the other dimensions of the block did not experience notable changes. On the other hand, the desorption of the hydrogel block without contact and only exposed to air underwent changes in all three dimensions. The hydrogel block with contact with cementitious substrate is subjected to the capillary forces at the interface and these forces provide adhesion between the hydrogel block and the substrate, thereby constraining the deformation in the planar dimension normal to the thickness direction. The significantly higher desorption rate of the hydrogel block with contact with the cementitious substrate compared to that without contact is attributed to the capillary effect. It is postulated that the Laplace pressure developed on the hydrogel at the interface accelerates the desorption of the hydrogel block. Since the capillary force decreases with increasing pore size, higher capillary forces are expected to develop in cementitious substrate with nanoscale pores than in the ceramic substrate with microscale pores. Also, it is seen from Figure 3 that the hydrogel block with contact with the porous ceramic exhibited some changes in the planar dimension. This indicates a smaller adhesion at the interface due to smaller capillary forces as discussed previously.

\section{Degree of hydration}

The non-evaporable water content $\left(\mathrm{W}_{\mathrm{n}}\right)$ of the control cement paste and the cement paste with hydrogel particles (SAP) is shown in Figure 5. It is seen that $\mathrm{W}_{\mathrm{n}}$ of the control cement paste was slightly higher than that of the cement paste with SAP at 6 days. This difference, however, seemed to diminish at later ages and both cement pastes showed a similar degree of hydration at 28 days of age. The slightly lower degree of hydration of the cement paste with SAP could be attributed to the reserved water in SAP particles at 6 days decreasing the effective water/cement ratio of the cement paste. As remaining water in SAP particles continued to release into the cement paste, the degree of hydration of the cement paste with SAP is expected to reach that of the control cement paste. 


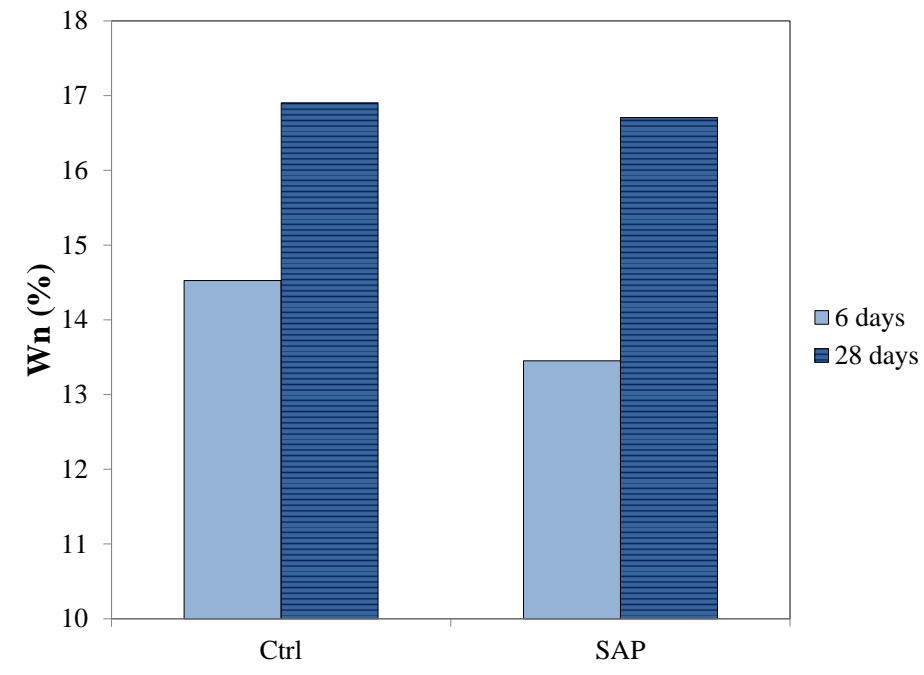

Figure 5. Non-evaporable water contents $\left(W_{n}\right)$ of the control cement paste and the cement paste with SAP at 6 days and 28 days of age.

\section{Compressive strength}

The compressive strength of the cement pastes at 6 days and 28 days of age is presented in Figure 6 . It is noted that the compressive strength of the cement paste with SAP was decreased compared to that of the control cement paste at both 6 days and 28 days of age. The decrease in compressive strength could be due to the formation of macrovoids in the cement paste with SAP as a result of SAP particles desorption. It appeared that the reduction in compressive strength due to macrovoid formation was more dominant than possible improvement in compressive strength due to microstructure densification surrounding SAP particles.

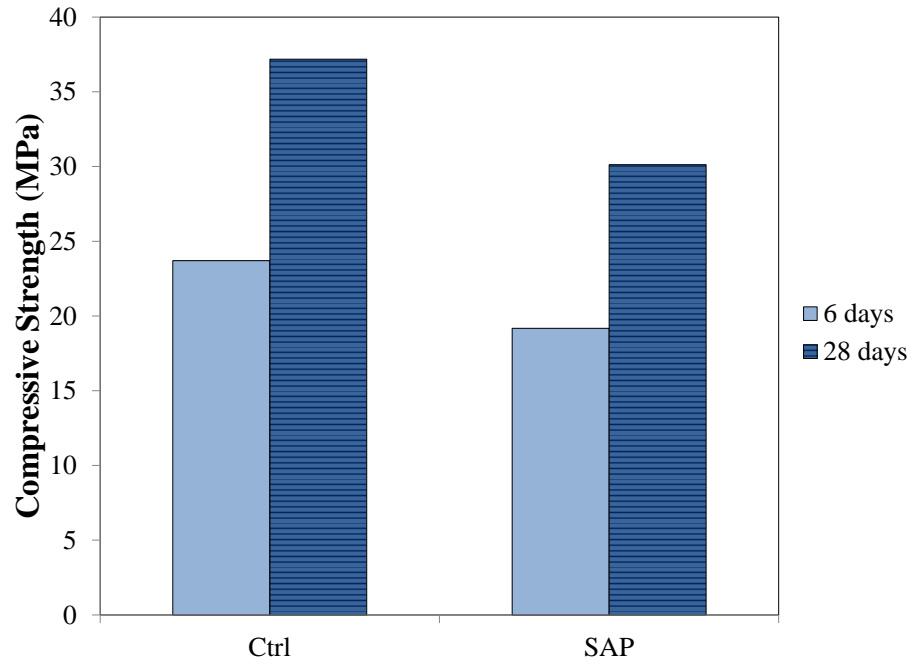

Figure 6. Compressive strengths of the control cement paste and the cement paste with SAP at 6 days and 28 days of age. 


\section{Electrical resistivity}

The electrical resistivity of the control cement paste and the cement paste with SAP is shown in Figure 7. It is seen that addition of SAP resulted in an increase in the electrical resistivity of the cement pastes at 6 days and 28 days of age. The improvement in the electrical resistivity could be attributed to a reduction in the effective water/cement ratio in the cement pastes resulting in microstructure refinement in the cement paste with SAP. Since electrical resistivity is used to assess the transport behavior and durability of cementitious materials, the results of electrical resistivity measurement presented in Figure 7 indicated that addition of SAP could enhance the durability of cementitious materials.

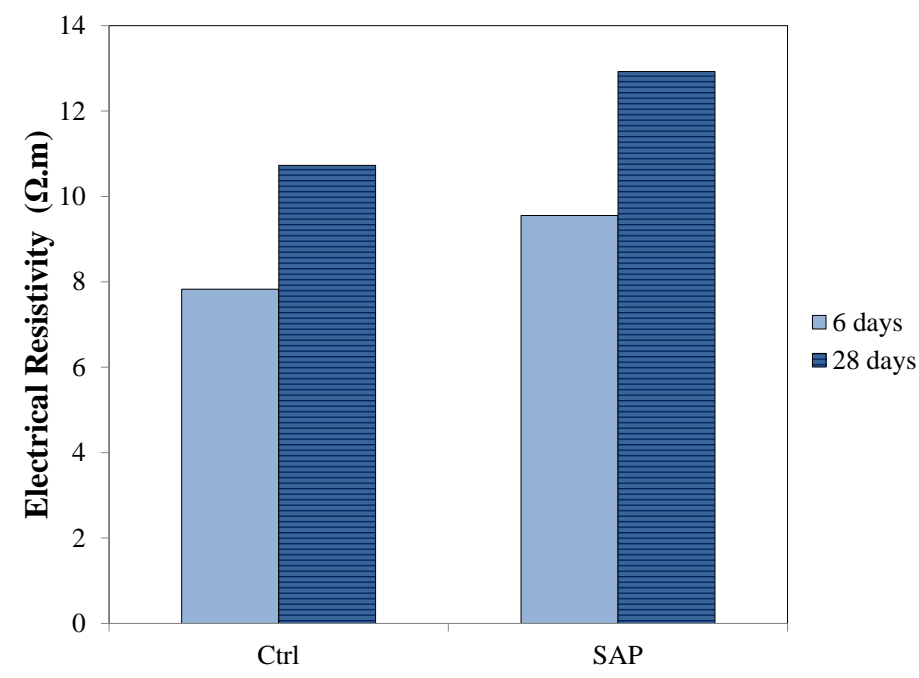

Figure 7. Electrical resistivity of the control cement paste and the cement paste with SAP.

\section{CONCLUSIONS}

The effect of ionic solutions and mechanical pressure on the absorption behavior of hydrogel particles was studied. It was shown that the absorption of hydrogel particles is strongly affected by the mechanical pressure applied to them. This is of important implication in the design of internal curing applications. The desorption of hydrogels with contact with porous substrates of different pore sizes was examined and the effect of capillary forces on accelerating desorption were discussed. It was observed that addition of SAP at the same total water/cement ratio improved electrical resistivity but decreased the compressive strength of the cement pastes more likely due to macrovoid formation.

\section{REFERENCES}

A. Pourjavadi, S.M. Fakoorpoor, P. Hosseini, A. Khaloo, Interactions between superabsorbent polymers and cement-based composites incorporating colloidal silica nanoparticles, Cem. Concr. Compos. 37 (2013) 196-204.

B.Y.K. Kovler, O.L.E.M. Jensen, Novel techniques for concrete curing, Concr. Int. (2005) 3942. 
C. Schröfl, V. Mechtcherine, M. Gorges, Relation between the molecular structure and the efficiency of superabsorbent polymers (SAP) as concrete admixture to mitigate autogenous shrinkage, Cem. Concr. Res. 42 (2012) 865-873.

D. Snoeck, D. Schaubroeck, P. Dubruel, N. De Belie, Effect of high amounts of superabsorbent polymers and additional water on the workability, microstructure and strength of mortars with a water-to-cement ratio of 0.50, Constr. Build. Mater. 72 (2014) 148-157.

D.P. Bentz, Influence of internal curing using lightweight aggregates on interfacial transition zone percolation and chloride ingress in mortars, Cem. Concr. Compos. 31 (2009) 285-289.

E.J. Garboczi, D.I. Bentz, Modelling of the microstructure properties of concrete, Constr. Build. Mater. 10 (1996) 293-300.

F. Horkay, I. Tasaki, P.J. Basser, Effect of monovalent - divalent cation exchange on the swelling of polyacrylate hydrogels in physiological salt solutions, Biomacromolecules. 2 (2001) 195-199.

F. Horkay, I. Tasaki, P.J. Basser, Osmotic swelling of polyacrylate hydrogels in physiological salt solutions, Biomacromolecules. 1 (2000) 84-90.

G.R. de Sensale, A.F. Goncalves, Effects of fine lwa and sap as internal water curing agents, Int. J. Concr. Struct. Mater. 8 (2014) 229-238.

J. Jain, N. Neithalath, Electrical impedance analysis based quantification of microstructural changes in concretes due to non-steady state chloride migration, Mater. Chem. Phys. 129 (2011) 569-579.

L. Dudziak, V. Mechtcherine, S. Hempel, Mitigating early age shrinkage of ultra-high performance concrete by using super absorbent polymers (SAP), Creep Shrinkage and Durability Mechanics of Concrete and Concrete Structures, Taylor \& Francis, (2008) 847853.

M.T. Hasholt, O.M. Jensen, Chloride migration in concrete with superabsorbent polymers, Cem. Concr. Compos. 55 (2015) 290-297.

N. Neithalath, J. Jain, Relating rapid chloride transport parameters of concretes to microstructural features extracted from electrical impedance, Cem. Concr. Res. 40 (2010) 1041-1051.

O.M. Jensen, P.F. Hansen, Water-entrained cement-based materials I . Principles and theoretical background, Cem. Concr. Res. 31 (2001) 647-654.

O.M. Jensen, P.F. Hansen, Water-entrained cement-based materials II. Experimental observations, Cem. Concr. Res. 32 (2002) 973-978.

P. Lura, F. Durand, A. Loukili, K. Kovler, Compressive strength of cement pastes and mortars with superabsorbent polymers, International RILEM Conference on Volume Changes of Hardening Concrete: Testing and Mitigation. (2006) 117 - 125.

S. Igarashi, A. Watanabe, O.M. Jensen, P. Lura, K. Kovler, Experimental study on prevention of autogenous deformation by internal curing using super-absorbent polymer particles, International RILEM Conference on Volume Changes of Hardening Concrete: Testing and Mitigation. (2006) 77-86. 
V. Mechtcherine, H.-W. Reinhardt, Application of super absorbent polymers (sap) in concrete construction, Springer, 2012.

V. Mechtcherine, L. Dudziak, J. Schulze, H. Staehr, Internal curing by Superabsorbent Polymers (SAP) - Effects on material properties of self-compacting fibre-reinforced high performance concrete, International RILEM Conference on Volume Changes of Hardening Concrete:

Testing and Mitigation. (2006), 87-96. 